\title{
European Nuclear Energy Agency
}

\section{Einar Saeland Director General}

The European Nuclear Energy Agency (ENEA) is a specialised agency of the Organization for Economic Cooperation and Development (OECD). The Agency was set up in December 1957 by OECD's predecessor, the "Marshall Plan" Organization (OEEC) to "... further the development of the production and uses of nuclear energy for peaceful purposes by the participating countries". Present membership of ENEA comprises 18 European countries * with Canada, Japan and the United States as Associate Members.

The creation of ENEA marked the culmination of studies within OEEC, begun in 1953, to find a solution to the problem of meeting Europe's growing energy demands. The urgency of this problem created a favourable climate for intergovernmental consultation and action, with the result that ENEA's life began with a programme of highly practical work. An essentially practical approach has since remained a characteristic of the Agency's activities, which can be broadly classified under four main headings:

- Promotion of major technological developments

- Interchange of specialist knowledge and provision of specialist information services on a joint basis

- Studies of reactor characteristics, fuel supplies and other factors relevant to the future role of nuclear power

- Work towards the evolution in Europe of a uniform legal regime governing "uses of nuclear energy for peaceful purposes in Member countries".

\section{Technological Development}

ENEA has sponsored three major joint undertakings in applied technology: the Halden Boiling Heavy Water

- Austria, Belgium, Denmark, France, German Federal Republic, Greece, Iceland, Ireland, Italy, Luxembourg, Netherlands, Norway, Portugal, Spain, Sweden, Switzerland, Turkey and the United Kingdom.
Reactor Project in Norway, the Dragon High Temperature Reactor Project at Winfrith (UK), and the Eurochemic Fuel Reprocessing Company at $\mathrm{Mol}$ in Belgium. These three undertakings together represent an investment of some $\$ 150$ million.

Both Halden and Dragon were originally set up (in 1958 and 1959 respectively) to investigate the practical possibilities of the reactor types concerned. However both have now reached the stage where their experimental installations are mainly devoted to developing and testing advanced types of fuel and fuel elements. The basic reactor technologies have been proven, in the case of Dragon with such impact that a number of electricity producers have shown interest, and several European industrial groups have announced that they are ready to design and build Dragon-type power stations. It is estimated that such stations should have construction costs between $\$ 100$ and $\$ 115$ per installed electrical kilowatt, and should produce power at between 0.35 and 0.45 cents per kWh. (Estimates based on 20 years amortisation period, $7.5 \%$ interest rate, and $75 \%$ load factor.)

Developments at Halden have been less concerned with a single reactor type and more with the technology of boiling reactors generally; for example reactor physics, dynamics, and the physical and chemical phenomena associated with boiling at the surface of fuel elements.

ENEA's third major joint undertaking, the Eurochemic Company*, was constituted in July 1959 under a Convention signed some 18 months previously. The Company's complex reprocessing plant at Mol, which came into service in 1966, is probably the most versatile such installation in the world, being designed to accept fuels with almost any composition, cladding,

- The Eurochemic Company is unique among the ENEA enterprises in that it has its own legal personality: the Halden and Dragon Projects are host organizations, the Norwegian Institutt for Atomenergi and the UK Atomic Energy Authority. legally established within the framework of their or physical shape. To date, it has treated more than 70 tonnes of natural or low-enriched uranium, and some 7 tonnes of highly-enriched uranium fuels. Eurochemic has also contributed to the development of a number of specialised chemical processes of importance for the treatment of irradiated fuels.

\section{Specialized Information}

Nuclear energy, like all other fields of science and technology, suffers from the problems of information acquisition, classification, storage and retrieval. Additionnally, much of the basic data of reactor design - particularly cross-sections - demands highly specialised laboratory equipment for its measurement.

These problems were recognised many years ago, and a first collaborative effort in the nuclear data field was the establishment, in 1956, of a Tripartite Nuclear Cross-Sections Committee (TNCC) by the United States, Canada and the United Kingdom. Soon after the formation of ENEA it was proposed to enlarge this Committee to include other countries, and in 1959 the Agency-sponsored European-American Nuclear Data Committee (EANDC) was set up. This Committee, comprising experts representing all OECD countries, keeps under review world developments in nuclear data measurements, together with requirements for new measurements in its supporting countries, recommending priorities for such new measurements and where they should be carried out. The Committee also helps to arrange the pooling and exchange of personnel and equipment where this appears advantageous.

Partly as a result of the work of EANDC, as well as from growing collaboration between Europe and North America in developing new forms of specialized collaboration in the handling of nuclear energy information, ENEA's Neutron Data Compilation Centre was established in 1964 at Saclay, France. Here the results of neutron data measurements from all over the world are collected, classified and stored in a computercontrolled electronic filing system while a bibliographical reference file (also electronic) of published reports of the measurement experiments is also maintained.

A second "Common Service" established by ENEA, also in 1964, is the Computer Programme Library (CPL) at Ispra, Italy. Here computer programmes for nuclear reactor calculations are collected from Europe, 
North America and Japan, checked and then made available on demand.

Other specialised technical cooperation between OECD countries takes place in the European-American Committee on Reactor Physics (EACRP) which is similar to EANDC in structure and method of work. Among the subjects recently dealt with by this Committee are light water reactor lattices, the physics of thorium-burning reactors, fuel burn-up calculations, and fast reactor physics. International liaison committees have also been set up for the magnetohydrodynamic and thermionic methods of direct conversion. These two Committees are now jointly sponsored by ENEA and the IAEA.

Lastly, the importance of exchanging knowledge and experience of reactor safety technology led, in 1965, to the creation of the Committee on Reactor Safety Technology (CREST).

\section{Future Role of Nuclear Power}

During the past years ENEA has carried out a series of studies on the future role of nuclear energy in Western Europe. Basically, these studies, which are continuing, are aimed at establishing probable relationships between expanding nuclear power programmes and resulting demands for fuel supplies (uranium and thorium), fuel production capacity, and other services such as enrichment and reprocessing. The studies relating to fuel resources and production, matters on which Europe cannot be considered in isolation from the rest of the world, are made in collaboration with the International Atomic Energy Agency.

\section{Legal Work}

From its earliest days, ENEA has been closely concerned with the development of regulations governing such matters as health and safety, transport of radioactive materials, or liability in case of accident. In particular, the first international Convention governing liability in case of a nuclear "incident" - the Paris Convention on Third Party Liability in the Field of Nuclear Energy - was developed under the auspices of the Agency. This Convention, which defined for the first time the underlying principles of all international agreements on nuclear liability, and also of most national legislation in this field, has been signed by 16 ENEA countries, and came into force in April 1968. It is the only international Convention at present operative in this field.

\section{The Future}

At a time when many nuclear energy programmes are undergoing substantial reappraisal, it has been particularly encouraging for ENEA that the mandates of all three of its major joint undertakings, Halden, Dragon and Eurochemic, have recently been extended (to December 1972, March 1973 and December 1974 respectively). The future of the Neutron Data Compilation Centre at Saclay and the Computer Programme Library at Ispra has also been confirmed by continuing support from participant countries and ever-increasing demands for their services. Requirements for other specialized services, perhaps operating on a similar basis, are under study, and ENEA is currently examining the whole question of nuclear information and data handling in relation to the recently established "INIS" (International Nuclear Information Service) of the IAEA.

It is clear that the demand for services of this nature will continue to expand. It is also apparent that, although nuclear energy is passing rapidly into the purely commercial stage, there remain certain fields such as fast reactors - where governmental action may still be needed.

There is also, of course, a growing interest in the problems of radioactive waste management, which by nature are essentially international. ENEA has been active in this field for some years and has, for example, organized two international operations (in 1967 and 1969) for the disposal of packaged solid wastes in the deep Atlantic. Work on problems of waste management is being expanded.

Finally, there is still a great deal of legal work to be done to resolve the many possible sources of conflict between the comparatively recent nuclear conventions (particularly the Paris Liability Convention) and traditional international and national laws. Nowhere is this more true than in the matter of transport at sea of nuclear substances, where nuclear law and maritime law can at present be in serious conflict. This is a matter, among others, in which ENEA is presently very active and may be expected to continue so.

In fact there seems no lack of new and continuing work in pursuit of ENEA's objectives quoted at the start of this article. Perhaps the Agency's most important asset in approaching this work is its extremely flexible framework, enabling methods for any particular joint activity to be adapted exactly to the requirements of individual situations.
Meetings

Notification of the following meetings to be held up to the end of December 1970 has been received. The meetings announced are in addition to those advertised in previous issues of Europhysics News. They are listed - date; title; venue; contact for information. Those organized by. Divisions of the EPS are printed in bold type and boxed; those sponsored by the EPS are printed in bold type. Europhysics Conferences (see Europhysics News No. 7) are indicated by a star following the date, and will be repeated.

\section{5 - 19 June * \\ Atomic Transport in Solids and Liquids \\ Marstrand, Sweden \\ A. Lodding, Arkitektvägen 6B, S-43080 Hovas}

24 - 26 June

Anelastic Properties of Solids

Lausanne, Switzerland

B. Vittoz, Ecole Polytechnique Fédérale

33, av. de Cour, $\mathrm{CH}-1007$ Lausanne

5 - 6 July

Annual Meeting of the Israel Physical Society

Tel Aviv, Israel

A.J. Greenfield, Secretary, Israe

Physical Society, Bar - Ilan

University, Ramat-Gan

\section{4 - 17 July \\ 2nd Conference on Atomic Spectroscopy and Related Topics \\ Hannover, Federal Republic of Germany \\ Conference on Atomic Spectroscopy, Institut A für Experimentalphysik, Technische Universität, Welfengarten 1, D-3 Hannover}

22 - 24 July *

Coherent Tunable Light Sources

Munich, Federal Republic of Germany

J. Schubert, Siemens AG, Research Laboratories 43, Hofmannstr. 51, D-8000 München 25

\section{4 - 11 August}

The Motion, Evolution of Orbits, and Origin of Comets

Leningrad, USSR

G.A. Chebotarev, Institute for Theoretical Astronomy, Mendelejevskaja

Linia 1, Leningrad B-164

\section{6 - 7 August}

The Crab Nebula

Jodrell Bank, UK

F. Graham Smith, Nuffield Radio Astronomy Lab., Jodrell Bank Macclesfield, Cheshire

\section{0 - 14 August}

External Galaxies and Quasi Stellar Objects Uppsala, Sweden

M. Schmidt, Mount Wilson and Palomar Observ. atories, 1201 East California Boulevard, Pasadena, Calif. 91106, USA

\section{$10-14$ August}

New Techniques in Space Astronomy

Munich, Federal Republic of Germany

R. Lüst, Institut für Extraterrestrische Physik, D-8046 Garching/München

\section{0 - 15 August}

White Dwarfs

St. Andrews, UK

W.J. Luyten, 221 Space Science Building, University of Minnesota, Minn. 55455, USA

\section{1 - 14 August}

Gravitational n-body Problem

Cambridge, UK

G. Contopoulos, University of Thessaloniki, Thessaloniki, Greece 